\title{
Novice Nurses Perception of Job Stress Working at Hospital at Tertiary Hospital
}

Mohummad Alamgir Kabir", Musammat Sultana Razia

Master of Science in Nursing (Nursing Management), National Institute of Advanced Nursing Education (NIANER), Bangladesh

Article History

Received: 23.07.2020

Accepted: 17.08 .2020

Published: 14.10 .2020

Journal homepage:

https://www.easpublisher.com/easjnm

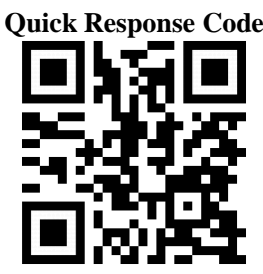

Abstract: Background: Stress is state of mental or emotional strain or tension resulting from adverse or demanding circumstances. Novice nurses perception of job stress is a global concern and work-related stress has the potential to negatively affect the individual's psychological and physical health, as well as an organization's effectiveness. Objectives: The aim of the present study was to examine thelevel of novice nurses perception of job stress working at hospital. Method: Simple convenience technique was used for this study and sample size was 108. The study was carried out within the period of March 25, 2017 to April 7, 2018. Data was collected by using self-structured questionnaire. The method of data collection was self-admitted questionnaire. Data was analyzed by both descriptive and inferential statistics by using SPSS version 23. Result: Results revealed that the most stressful event was the uncertainty concerning the treatment, workload, death and dying, followed by problems with supervisors, conflict with physicians, problems with peers, inadequate emotional preparation, patients and their families and discrimination. Nurses working in medicine ward and emergency department had high level of stress job stress compared with than nurses who were working in the other wards. Conclusion: The study concludes that nurse managers in hospitals should develop programs to reduce job stress of novice nurses through in-service education program or and also conduct more systematic survey to better understand the work stress of not only novice nurses related to clinical practice job stress but also other nurses.

Keywords: Novice, Nurses, Job Stress and Perception.

Copyright (C) 2020 The Author(s): This is an open-access article distributed under the terms of the Creative Commons Attribution 4.0 International License (CC BY-NC 4.0) which permits unrestricted use, distribution, and reproduction in any medium for non-commercial use provided the original author and source are credited.

\section{INTRODUCTION}

Stress is a common phenomenon that affects anyone's life. Among all health care professionals, nursing is said to be a highly ranking profession who are the victims of stress [1]. Novice nurses experience of job stress is a global concern and work-related stress has the potential to negatively affect the individual's psychological and physical health, as well as an organization's effectiveness. It is recognized worldwide as a major challenge to workers' health and the functioning of their organizations. Nurses who are newly entering in the profession often fall a victim for it and many feel to quit/ renounce the job itself [1].

Nursing is said to be a top risky profession who are the victims of stress, among all health care professionals. Novice nurses have a period of transition before they become competent to provide patient care. It is very laborious for the novice nurses to get orientation about the new work environment, rendering patient care, learning new roles and responsibilities, meeting the expectation of colleagues and superiors. One study shown that frequent stressful event was rated to be the uncertainty concerning the treatment, workload, death and dying, problems with supervisors, conflict with physicians, problems with peers, inadequate emotional preparation, patients and their families and discrimination [1]

Novice nurses are victim to face multiple challenges while beginning as practical nurses which resulted in work incompetence, high level of burn out and depersonalization among them as compare to their experienced counter partners [2]. Different challenges of the novice nurses were identified to be different for various procedures, policies and skills. One study shown that novice nurses faced different challenges during the first year of their career including work load, lack of confidence, lack of communication skills, and little knowledge about different procedures, time management and low competency level in performing certain clinical skills [3].

Changes in role ambiguity, role conflict, and role overload across time as predictors of intention to quit among nurses. Retention of nursing staff has become a major challenge to employers. Intention to quit is a powerful predictor of turnover among nurses, as well as other professions. A study on the predictors 
of intention to quit have paid little attention to role stressors because they influence intention to quit or on the extent to which changes across time in stressors are associated with intention to quit [4].

One surveys shown the importance of the preceptor and manager in the perceived success of this generation's transition and a need to assimilate into the professional role of $\mathrm{RN}$. Recognizing that there is a need to promote a more individualized orientation with improved mentoring for novice nurses and their preceptors is evident and challenges nursing leaders and educators to rethink current practices to retain new nurses. The roles of the hospital and individual nursing units are changing strategies for recruitment and retention no longer apply. A structured orientation can facilitate the transition from new graduate to professional nurse and assist in the retention of qualified nurses and ultimately safe patient care [5].

Novice nurses may be at greater risk for errors than experienced nurses. Because the novice nurses perform nursing activities into practice, it is necessary to recognize potential mistakes in order to prevent stress. The role of transition from student to staff nurse is difficult because they are not adequately prepared. For this reason, researcher would like to explore the Job Stress of Novice Nurses Working at Hospital.

\section{ObJective OF The Study}

The aim of the study is to examine the job stress of novice nurses working at hospital.

\section{Specific Objectives}

a. To assess the level of job stress among novice nurses at hospital.

b. To examine the relationship between sociodemographic characteristics and job stress among novice nurses at hospital.

\section{MeTHODS}

Study Design: Descriptive study design was done to explore the level of job stress of novice nurses working at hospital.

Study Participants: In this study, the sample was conveniently selected from the novice nurses working at Sir Salimullah Medical College Hospital who met the following inclusion criteria

a. Educational background had at least diploma in nursing and midwifery $b$. Nurses with experience at least from one year to one year six months c. Nurses who were working in five major departments 1 . Emergency department 2. Surgery Unit, 3. Medicine Unit, 4. ICU. 5. CCU.

d. Subjects who had willing to participate in the study. The sample size was estimated by using " $G$ " power analysis. Researcher's use the level of significance $(\alpha)$ of 0.05 , expected power $0.80(1-\beta)$ and medium size effect $0.3(\gamma)$. Sample size was 108 .

Instrument: A set of structure questionnaire was developed by the researcher according to literature reviewed for collecting the data. The instrument consists of three parts: Part I: The Demographic Data Questionnaire (DDQ): included 5 items such as age, gender, religion, marital status and education. Part II: Job Related Questionnaire (JRQ) included5 items including service experience, wards, ever experience, continuing education and hospital policy. Part III: Nurses Perception of Job Stress Questionnaire (NPJSQ): included 12items. Three experts were examined the Nurses Perception Job Stress Questionnaire 1) Expert from Korea of Faculty of Nursing Management at NIANER2) Faculty of Nursing Management at NIANER 3) Nursing superintendent or Nurse Supervisor who had knowledge regarding nursing research and administration and also who had completed Master degree program in nursing field. They were asked to check the relevancy of the questions on the scale of job stress in the context of Bangladesh.

\section{Data Collection Methods}

Permission was obtained from IRB at NIANER and BSMMU (IRB No. 5-201801).Permission was obtained from Director and Nursing Superintendent of SSMCH. Verbal and written consent was taken from the participants. After getting permission from the concerned authority and subjects then researcher met with nursing superintendent and nursing supervisor for helping the data collection after that they went to the selected department with nursing supervisors and introduced with ward in-charge and then explained the aim of the study with novice nurse after that researcher distributed 108 Bangla version questionnaire and data was collected by selfadministered questionnaire from each subjects. The duration of data collection was from March 25, 2018 to April 07, 2018.

\section{Data Analysis}

Data was analyzed by using SPSS version 23.a. Descriptive statistics including frequencies, percentages, mean, and standard deviation was used to describe the sample characteristics. B. Pearson Correlation Coefficient, t-test and ANOVA was used to test the relationship between nurse's job stress and the samples demographic characteristics.

\section{RESUlTS}

This chapter summarizes the results of study. The findings of the study are described under the following headings including (1) demographic characteristics; (2) job characteristic, (3) relationship between demographic characteristics and job Stress and 
(4) relationship between Job Characteristics and Job Stress of the subjects.

\section{Demographic characteristic of the subjects}

Table 1 showed that majority of the subjects age range was from 22 to 35 years with a mean of 28.20 years old $(\mathrm{SD}=3.102)$. The most of the subjects were female $(79.6 \%)$ only few numbers of subjects were male $(21.3 \%)$.About two thirds of the subjects were Muslims $(77.8 \%)$, Hindus were $(21.3 \%)$ only $(.9 \%)$ subjects were Christian. Most of the subjects were married $(85,2 \%)$ only $(14.8 \%)$ subjects were single. The study results showed that $92(85.2 \%)$ nurses educational background was only diploma in nursing. Rest of nurses 16(14.8) educational background was $\mathrm{BSc}$ in nursing.

Table-1: Distribution of Demographic Characteristics of the Subjects ( $n=108$ )

\begin{tabular}{|r|r|r|}
\hline Variable & $\mathbf{N}(\boldsymbol{\%})$ & $\mathbf{M} \pm$ SD \\
\hline Age (Years) & & $28.20(3.102)$ \\
\hline $22-25$ & $23(21.3)$ & \\
\hline $26-30$ & $61(56.5)$ & \\
\hline $31-35$ & $24(22.2)$ & \\
\hline Sex & & \\
\hline Male & $22(20.4)$ & \\
\hline Female & $86(79.6)$ & \\
\hline Religion & & \\
\hline Muslim & $84(77.8)$ & \\
\hline Hindu & $23(21.3)$ & \\
\hline Christian & $1(.9)$ & \\
\hline Marital status & & \\
Single & $16(14.8)$ & \\
Married & $92(85.2)$ & \\
\hline Education & & \\
\hline Diploma in Nursing & $92(85.2)$ & \\
BSc in Nursing & $16(14.8)$ & \\
\hline
\end{tabular}

\section{Job characteristics of the subjects}

Table 2 shows that most of the subjects $(50 \%)$ were working at medicine ward.15.7\% subjects were working at surgery ward, 16 (14.9) subjects were working at emergency ward and (19.4\%) subjects were working at ICU and CCU wards. However, study result revealed that $(100 \%)$ nurses had ever experience related to stress. Among them $100 \%$ nurses did not get any continuing education training after getting job. Hence $(100 \%)$ nurses rated the item hospital policy there had no any policy in hospital that related to stress management.

Table-2: Distribution of Nurses Job Characteristics ( $n=108$ )

\begin{tabular}{|l|l|c|c|}
\hline Variables & Category & N (\%) & M (SD) \\
\hline Working ward & & & \\
\hline & Surgery & $17(15.7)$ & $28.75 \pm 6.170$ \\
\hline & Medicine & $54(50.0)$ & $32.41 \pm 5.127$ \\
\hline & Emergency & $16(14.9)$ & $27.25 \pm 5.119$ \\
\hline & ICU & $13(12.0)$ & $29.62 \pm 6.475$ \\
\hline Ever experience stress & Yes & $08(7.4)$ & $26.63 \pm 8.017$ \\
\hline & No & $108(100)$ & $1.00(.00)$ \\
\hline Continue education & & & \\
\hline & Yes & & \\
\hline & No & $108(100)$ & $.00(.00)$ \\
\hline Hospital policy & & & \\
\hline & Yes & & \\
\hline & No & $108(100)$ & $.00(.00)$ \\
\hline
\end{tabular}

\section{Level of job Stress of the subjects}

Table 3 reveals that the most of the novice nurses had high level of clinical stress $(30.317 \pm 6.027)$ related to Patient suffering $(\mathrm{M}=3.30, \mathrm{SD}=.701)$ whereas very few nurses rated very low level of clinical stress. It was also found that provide emotional support
$(\mathrm{M}=3.25, \mathrm{SD}=.766)$, in adequate preparation $(\mathrm{M}=2.78$, $\mathrm{SD}=.846)$, death and dying $(\mathrm{M}=2.75$, SD.763), uncertainty concerning $(\mathrm{M}=2.58$, SD.887), workload $(\mathrm{M}=2.46, \mathrm{SD}=.932)$, inadequate information $(\mathrm{M}=2.46$, $\mathrm{SD}=.880)$, criticize by physician $(\mathrm{M}=2.27, \mathrm{SD}=.849)$, patient and their families $(M=2.26, \quad S D=.961)$, 
discrimination $(\mathrm{M}=2.16, \mathrm{SD}=.877)$ and problem with peers $(\mathrm{M}=2.03, \mathrm{SD}=.859)$. The least number of participants rated stressful experience related to problem with supervisors $(\mathrm{M}=2.02, \mathrm{SD}=.864)$.

Table-3: Job stress of the subjects $(n=108)$

\begin{tabular}{|c|c|c|c|c|c|}
\hline Variables & $\begin{array}{l}\text { Very low } \\
\text { n }(\%)\end{array}$ & $\begin{array}{l}\text { Low } \\
\text { n }(\%)\end{array}$ & $\begin{array}{l}\text { High } \\
\text { n (\%) }\end{array}$ & $\begin{array}{l}\text { Very high } \\
\text { n }(\%)\end{array}$ & $\mathbf{M} \pm \mathrm{SD}$ \\
\hline Death and dying & $6(5.6)$ & $30(27.8)$ & $57(52.8)$ & $15(13.9)$ & $2.75 \pm .763$ \\
\hline Criticize by physician & $22(20.4)$ & $41(38.0)$ & $39(36.1)$ & $6(5.6)$ & $2.27 \pm .849$ \\
\hline Problem with peers & $35(32.4)$ & $38(35.2)$ & $32(29.6)$ & $3(2.8)$ & $2.03 \pm .859$ \\
\hline Inadequate preparation & $7(6.5)$ & $32(29.6)$ & $47(43.5)$ & $22(20.4)$ & $2.78 \pm .846$ \\
\hline Inadequate information & $17(15.7)$ & $35(32.4)$ & $45(41.7)$ & $11(10.2)$ & $2.46 \pm .880$ \\
\hline Problem with supervisors & $32(29 / 6)$ & $49(45.4)$ & $20(18.5)$ & $7(6.5)$ & $2.02 \pm .864$ \\
\hline Workload & $17(15.7)$ & $40(37.0)$ & $35(32.4)$ & $16(14.8)$ & $2.46 \pm .932$ \\
\hline Uncertainty concerning treatment & $13(12)$ & $35(32.4)$ & $44(40.7)$ & $16(14.8)$ & $2.58 \pm .887$ \\
\hline Patient and their families & $29(26.9)$ & $32(29.6)$ & $37(34.3)$ & $10(9.3)$ & $2.26 \pm .961$ \\
\hline Discrimination & $27(25.0)$ & $44(40.7)$ & $30(27.8)$ & $7(6.5)$ & $2.16 \pm .877$ \\
\hline Patient suffering & $2(1.9)$ & $9(8.3)$ & $52(48.1)$ & $45(41.7)$ & $3.30 \pm .701$ \\
\hline Provide emotional support & $4(3.7)$ & $9(8.3)$ & $50(46.3)$ & $44(40.7)$ & $3.25 \pm .766$ \\
\hline
\end{tabular}

Relationship between Demographic Characteristics and Job Stress

Table 4 shows that there is no significant relationship between demographic characteristics and job stress.

Table-4: Relationship between Demographic Characteristics and Job Stress of the subjects $(\mathrm{n}=108)$.

\begin{tabular}{|l|l|c|c|c|}
\hline Variable & Category & $\mathbf{M} \pm$ SD & $\mathbf{t} / \mathbf{r} / \mathbf{F}$ & $\boldsymbol{p}$ \\
\hline Age in years & $22-25$ & $32.22 \pm 5.32$ & 1.428 & .245 \\
\hline & $26-30$ & $29.91 \pm 5.88$ & & \\
\hline & $31-35$ & $29.58 \pm 6.83$ & & \\
\hline Sex & Male & $28.90 \pm 6.97$ & 1.233 & .220 \\
\hline & Female & $30.68 \pm 5.74$ & & \\
\hline Religion & Muslim & $29.83 \pm 6.08$ & 1.563 & .121 \\
\hline & Non-Muslim & $32.00 \pm 5.61$ & & \\
\hline Marital status & Single & $31.68 \pm 7.89$ & .781 & .445 \\
\hline & Married & $30.07 \pm 5.65$ & & \\
\hline Educational status & Diploma in Nursing & $30.28 \pm 6.30$ & .170 & .866 \\
\hline & BSC in Nursing & $30.50 \pm 4.30$ & & \\
\hline
\end{tabular}

Relationship between Job Characteristics and Job Stress

Table 5 reveals that there was a statistically significant relationship found among subjects who were working in medicine ward and emergency department had high level of job stress compared with those who were working in other wards $(F=4.169$, $p=.004)$.

Table-5: Relationship between Job Characteristics and Nurses Perception on Job Stress of the subjects $(\mathbf{n}=108)$.

\begin{tabular}{|l|l|c|c|c|}
\hline \multirow{2}{*}{ Variable } & & \multicolumn{3}{|c|}{ Perception } \\
\cline { 2 - 4 } & Category $^{\mathrm{a}} \mathrm{M} \pm \mathrm{SD}$ & $\mathrm{t} / \mathrm{r} / \mathrm{F}$ & $p$ \\
\hline ward & Medicine $^{\mathrm{a}}$ & $28.75 \pm 6.170$ & 4.169 & .004 \\
& Surgery $^{\mathrm{b}}$ & $32.41 \pm 5.127$ & & \multirow{2}{*}{$\mathrm{a}, \mathrm{c}>\mathrm{b}, \mathrm{d}, \mathrm{e}$} \\
& Emergency $^{\mathrm{c}}$ & $27.25 \pm 5.119$ & & \\
\hline & ICU $^{\mathrm{d}}$ & $29.62 \pm 6.475$ & & \\
\hline & $\mathrm{CCU}^{\mathrm{e}}$ & $26.63 \pm 8.017$ & & \\
\hline
\end{tabular}

\section{DiscuSSION}

This descriptive study was done to examine the Novice Nurses Perception on Job Stress and to examine the relationship between job stress and sociodemographic variables which was conducted in Sir Salimullah Medical College Hospital, Dhaka. In this section, the findings of the study are explained elaborately.

The study showed that among 108 novice nurses, age range was from 22 to 35 years with a mean of 28.20 years and $\mathrm{SD}=3,102$. The most of the subjects of female were $79.6 \%$., majority of the subjects were Muslim $77.8 \%$ and approximately most of the 
subjectsgot married $85,2 \%$ and the majority of the subjects were diploma in nursing $85.2 \%$.).Results demonstrated that the most of subjects $(50 \%)$ were working at medicine ward which was similar to the study conducted by Rajeswari \& Sreelekha [1], India. Their findings showed that $88 \%$ were in age group of 22 years, $8 \%$ in 21 years and $4 \%$ in 23 years. With regard to gender $92 \%$ were female, marital status $92 \%$ were single. In the level of educational qualification $80 \%$ was B.Sc (Nursing/PHN).In the place of work $67 \%$ work in ICU, $33 \%$ in wards, $10 \%$ in emergency department.

Findings of this study showed that novice nurses are related to the stressful situation as the component of their daily routine work activities. From most stressful to least stressful events were rated by the novice nurses. Frequent stressful event was rated to be the death and dying, criticize by physicians, problem with peers, inadequate preparation, inadequate information from a physician, problem with supervisors, work load, uncertainty concerning treatment, patients and their families, discrimination, patient suffering, provide emotional support. The most common stressful events were identified as patient suffering and provide emotional support. The most stressful events of patient suffering were $41.7 \%$ $(\mathrm{M}=3.30, \mathrm{SD}=.701)$ and provide emotional support was $40.7 \%$ ( $\mathrm{M}=3.25$, SD.766). This is similar to the study finding by Rajeswari \& Sreelekha [1]. The most common stressful events was identified as uncertainty concerning treatment $(\mathrm{M}=2.73, \mathrm{SD}=1.48)$ due to the fright of doing mistake in treating patient, inadequate experience and fear of physicians. In addition to the highest sources of stress were workload and patient death and dying by Ko, and Kiser-Larson [6].

This study showed that the least number of participants was rated stressful experience related to problem with supervisors $(\mathrm{M}=2.02$, $\mathrm{SD}=.864)$.According to the study of Rajeswari \& Sreelekha [1]they found that problems with supervisor is another factor of stress because newly appointed nurses expect the administrators to be supportive in their work and lack of support leading to workplace issues and the least rated stressful experience was discrimination $(\mathrm{M}=1.2, \mathrm{SD}=1.42)$ that discrimination and harassment are the least stress factor for nurses which are responsible by supervisor and peers.

According to the study of Rajeswari \& Sreelekha [1] workload is said to be a major stressor because more work is assigned among them, they were asked to continue the work, working with non- related nursing task, working long time without breaks and no emotional support to meet the needs of patient whereas this study findings of workload is $\mathrm{M}=2.46, \mathrm{SD}=.932$.

Adequate preparation and inadequate information are the stress factor for nurses which are responsible by supervisor, physician and peers which are related to increased demands at work, use of advanced equipments, inadequate staff and lack of independence in work are the main factors affecting the nurses and that was related to inadequate emotional preparation $\mathrm{M}=2.32, \mathrm{SD}=1.2$, [1]. During this critical period of professional development novice nurses face many challenges due to gaps in knowledge and skills, which may lead to early termination of their nursing careers. Khan et al. [3], whereas this study showed that adequate preparation was $\mathrm{M}=2.78, \mathrm{SD}=.846$ and inadequate information was $\mathrm{M}=2.46, \mathrm{SD}=.880$.

This study showed that death and dying was $\mathrm{M}=2.75, \mathrm{SD}=.763$. According to Rajeswari \& Sreelekha [1], death and dying was one of the most stressor because the nurses are not well prepared to face this stress and facilitating grief is not available. Kindly care on the patient could be a reason for the experience of stress. Ko and Kiser-Larson [6] identified that the highest sources of stress were workload and patient death and dying.

Criticize by physician is one of the most stressor due to unavailability of physician during emergency, criticize by doctors and unclear orders. Rajeswari \& Sreelekha [1] reported conflict with physicians was $\mathrm{M}=2.51, \mathrm{SD}=1.52$ whereas this study showed that criticize by physicians was $\mathrm{M}=2.27$ $\mathrm{SD}=.849$.

This study showed that problem with peers was $\mathrm{M}=2.03, \mathrm{SD}=.859$. According to Rajeswari \& Sreelekha [1] problems with peers is a main reason for stress because nurses can't share anything openly with peers and due to difference in their views, some nurses may find difficulty to work with a particular nurse.

This study showed that problem with patients and their families was $\mathrm{M}=2.26, \mathrm{SD}=.961$. Rajeswari \& Sreelekha [1] reported that conducting with patients and their families is mainly due to the demands from the family members and patients, whether families report the care is inadequate and managing visitors because it disturbs the care for the patient and also reported problem with patients and their families was $\mathrm{M}=2.24$, $\mathrm{SD}=1.59$.

This study showed that there was no association between demographic characteristics and clinical stress. Finding reveals that age $(p=.24)$, sex $(\mathrm{p}=.22)$, religion $(\mathrm{p}=.12)$, marital status $(\mathrm{p}=.44)$, and educational status $(\mathrm{p}=.86)$ had no significant relationship with novice nurses clinical stress (Table 4). In this study that novice nurses who were working in medicine ward and emergency department had significant relationship with clinical stress $(\mathrm{F}=4.169$, $\mathrm{p}=.004$ ) than other wards (Table 5) and also it depends on the specialized areas they are working which was related to the study conducted by Rajeswari \& 
Sreelekha [1] in the area of work, nurses working in ICUhad a significant association on the subscales of inadequate emotional preparation, problems with supervisors, death and dying and conflict with physicians, $(\mathrm{p}=0.01)$.

\section{CONCLUSION}

The study concludes that novice nurses experience a highest stress. Novice nurses frequently experience various stressful situations in the workplace that can lead to physical, mental, and psychosocial health problems. Managing stressor is vital to prevent employee turnover. Nurses must be able to care for themselves to maintain their optimal health conditions and to reduce or prevent stress at work. Motivation, cultivating confidence and promoting interpersonal skills will facilitate the reduction of stress and increases job satisfaction. Administrators need to have a special focus on the most stressful areas which formulating policies like as continuing education, training and higher education. Stress management strategies' need to be regularly implemented for nurses so that there is an increased productivity in terms of quality of patient care. It is evident that before entering into the clinical practices the novice nurses must be well prepared through a comprehensive orientation program, which will help in building a strong foundation for their professional growth. Therefore, the quality of patient care and the retention of nursing staff likely will improve.

\section{RECOMMENDATION}

The result of this study suggests that the following recommendation to be made to reduce the job stress of the novice nurses: a. nursing management must integrate actions towards guiding and supporting the novice nurses. b. Interventions are needed to help novice nurses increase their awareness of reduction of job stress. c. Proper selection, training and monitoring of preceptors is likely a key intervention. $d$. Communications relationship should be established among novice nurses, physician, nursing supervisor and peers. e. Supportive work environments should be established more by developing interventions including increasing the number of staff members, providing more breaks, and offering additional unit supervisor support. f. In-service training, workshops and seminars should be organized for novice nurses to update their knowledge and skills. g. Novice nurses should be sent for courses on human behavior resource management, interpersonal relation, stress management and crisis interventions. h. Continuous nursing educational (CNE) sessions should be conducted to enhance nursing skills.

\section{REFERENCES}

1. Rajeswari, H., \& Sreelekha, B. (2017). Novice nurses experience of clinical stress in a tertiary care teaching Hospital, Journal of Nursing and Health Science, 6(4), 54-60.

2. Watson, J., Macdonald, G. J., \& Brown, D. (2013). Clinical supervision for novice millennial nurses in the perinatal setting: The need for generational sensitivity. Open Journal of Nursing, 3(05), 373.

3. Khan, M. N., Zeb, A, K., \& Islam, F. (2017). Challenges of the novice nurses working in tertiary care cardiac hospital of Karachi Pakistan, International Journal of Scientific and Research Publications. 7(3), 100-103

4. Marom, M., \& Koslowsky, M.(2013). Relationships between changes in Role stressors and intention to quit among novice nurses, European Journal of Business and Social Sciences, 2(1), 1-14

5. Riegel, K. F. (2013). Foundations of dialectical psychology. Academic Press.

6. Ko, W., \& Kiser-Larson, N. (2015).Stress Levels of Nurses in Oncology Outpatient Units, Clinical Journal of Oncology Nursing, 20(2), 158-164. 